\title{
Dermatite digital bovina: etiologia e rotas de transmissão
}

\section{Etiology of bovine digital dermatitis and transmission routes}

\author{
Tiago Facury Moreira1* ${ }^{1 *}$ Elias Jorge Facury Filho², Leandro Silva Andrade ${ }^{2}$, Luiz Fernando Cardoso Labre ${ }^{1}$, \\ Karolliny Merlo Goehringer ${ }^{1}$, Otavio Luiz Fidelis Junior ${ }^{1}$, Letícia Marques Rodrigues ${ }^{1}$, Odael Spadeto Jùnior ${ }^{1}$, \\ Guilherme Vieira Fonseca², Antônio Ultimo Carvalho² \\ ${ }^{1}$ Universidade Vila Velha (UVV), Vila Velha, ES, Brasil \\ 2 Universidade Federal de Minas Gerais (UFMG), Belo Horizonte, MG, Brasil
}

\section{Resumo}

A dermatite digital (DD) é uma das principais doenças do sistema locomotor de bovinos que levam os animais à claudicação e causam graves prejuízos econômicos. Desde o seu primeiro relato na Itália, em 1974, a DD atingiu uma situação endêmica em diversos países, incluindo o Brasil. Bactérias do gênero Treponema são os principais agentes envolvidos, pois se apresentam como as bactérias mais abundantes e também estão presentes nas partes mais profundas das lesões. Mais de 20 espécies diferentes de Treponema foram identificados em amostras de DD, sendo as espécies T. pedis, T. medium, T. phagedenis, T. refringens e $T$. denticula as mais relatadas. Uma diversidade de outras bactérias como Mycoplasma, Fusobacterium, Porphyromonas, Bacteroides spp., Campylobacter spp., Guggenheimella spp. e D. nodosus também foram descritas. Tentativas de induzir a doença artificialmente só foram bem sucedidas com o uso de macerado de lesões ativas, demonstrando a importância do sinergismo bacteriano. Apesar da quantidade de estudos sobre o tema, a determinação da etiologia definitiva da DD permanece sendo um desafio, principalmente em relação ao papel que as diferentes bactérias encontradas desempenham no desenvolvimento da lesão. A epidemiologia desta doença também apresenta aspectos pouco esclarecidos, como os possíveis reservatórios e como ocorre a sua transmissão. Os filotipos de Treponema envolvidos na DD foram detectados na cavidade oral, rúmen, fezes e no ambiente de fazendas que possuíam a doença, porém sempre em pequenas quantidades, o que mantém em questão a importância destes locais como reservatórios.

Palavras-chave: Claudicação. Lesões podais. Treponema. Casco.

\begin{abstract}
Bovine Digital Dermatitis (DD) is one of the main causes of lameness in cattle, and lead to economic losses. Since first reported, in Italy in 1974, DD had spread all over
\end{abstract}


the world, reaching an endemic situation in several countries, including Brazil. Bacteria of the genus Treponema are the main agents involved, since it is present as the most abundant bacteria and in the deepest parts of the lesions. More than 20 different species of Treponema were identified in DD samples, being $\mathrm{T}$. pedis, T. medium, T. phagedenis, T. refringens and T. denticula the most reported. A variety of other bacteria such as Mycoplasma, Fusobacterium, Porphyromonas, Bacteroides spp., Campylobacter spp., Guggenheimella spp. and D. nodosus are also described. Attempts to artificially induce the disease were successful when using macerated active lesions, demonstrating the importance of bacterial synergy. Despite the number of studies on the topic, the determination of the definitive etiology of the DD remains a challenge, especially in relation to the role of the different bacteria found in the lesions. The epidemiology of this disease is also a challenge for researchers, especially regarding the possible reservoirs and disease transmission. The Treponema phylotypes involved in DD have already been detected in oral cavity, rumen, feces and in the environment of positive farms, but always in small amounts, what keeps the question regarding the importance of these sites as reservoirs.

Keywords: Lameness. Hoof lesions. Treponema. Hoof.

\section{Introdução}

A dermatite digital (DD), descrita por vários autores como a principal causa de claudicação em bovinos leiteiros em todo o mundo (Rasmussen et al., 2012; Santos et al., 2012; Nielsen et al., 2016), foi primeiramente citada em 1974 no Vale do Pó, região norte da Itália, em vacas Friesian (Cheli e Mortellaro, 1975). Nos Estados Unidos, foi relatada pela primeira vez em Nova York, por Rebhun et al. (1980), e rapidamente se espalhou para vários outros estados (Wilson-Welder et al., 2015a). No Reino Unido, a primeira descrição foi realizada por Blowey e Sharp (1988), e no Brasil foi relatada pela primeira vez no início da década 90 (Borges et al., 1992).

Desde o seu primeiro relato na Itália, a DD se tornou um problema crescente em vários países, sendo hoje a principal patologia podal dos bovinos (Klitgaard et al., 2014). O Sistema de Monitoramento
Nacional de Saúde Animal dos Estados Unidos (USDA) mostrou que mais de $50 \%$ dos casos de claudicação ocorridos em novilhas e vacas leiteiras tem como principal causa a DD (USDA, 2009), cujo prejuízo anual é estimado em US\$ 190 milhões. Cada caso clínico de DD causa um custo de US\$ 95, e quando as perdas de produção de leite e diminuição do desempenho reprodutivo são incorporados ao cálculo, as perdas são estimadas em US\$ 126 por caso clínico (USDA, 2009).

A DD é uma doença polimicrobiana, cuja etiologia ainda não é totalmente elucidada (Krull et al., 2014; Moreira et al., 2018). Espiroquetas do gênero Treponema são as bactérias mais prevalentes e são encontradas na parte mais profunda das lesões, na camada entre o tecido lesado e o saudável (Zinicola et al., 2015a; Nielsen et al., 2016; Moreira et al., 2018). No total, mais de 20 diferentes filotipos de Treponema foram identificados nas lesões de DD, destacando-se o Treponema phagedenis, Treponema refringens, Treponema medium/vincentii-like, Treponema denticola e Treponema pedis.

Como existe uma dificuldadeem cultivar bactérias do gênero Treponema, métodos independentes de cultura, tais como sequenciamento gênico, PCR e hibridização fluorescente in situ (FISH), têm sido utilizados com sucesso (Klitgaard et al., 2013).

Diversas outras bactérias também foram identificadas nas lesões de DD, como os gêneros $D$. nodosus (Rasmussen et al., 2012), Bacteroides spp., Campylobacter spp., Guggenheimella spp. (Zinicola et al., 2015b) e Mycoplasma, Fusobacterium, Porphyromonas (Nielsen et al., 2016; Moreira et al., 2018). Entretanto, o papel desempenhado por cada um destes grupos bacterianos no desenvolvimento da lesão não é bem conhecido.

A transmissão da DD dentro dos rebanhos e entre rebanhos não é totalmente esclarecida, assim como sua patogênese, que é o objetivo de diferentes estudos desde 1974. Considera-se que a entrada de animais de rebanhos positivos em rebanhos negativos para DD possa aumentar as chances de transmissão da doença (Rodriguez-Lainz etal,1999). Outra possível fonte de infecção entre rebanhos é pelo material utilizado para o casqueamento (Sullivan et al., 2014). A transmissão entre animais dentro da mesma fazenda é ainda menos elucidada. Diferentes estudos tentaram identificar bactérias 
relacionadas à DD nas fezes, reto, rúmen e no ambiente de animais com a presença da lesão e obtiveram resultados divergentes (Wilson-Welder et al, 2015a; Zinicola et al., 2015b).

0 objetivo da presente revisão de literatura é discorrer sobre a etiologia, rotas de transmissão e possíveis reservatórios da dermatite digital bovina.

\section{Dermatite digital}

A DD também é conhecida como doença de Mortellaro, verruga do talão, papilomatose interdigital ou calcanhar em amora, e caracterizase por uma inflamação superficial contagiosa da epiderme próxima à margem coronariana no espaço interdigital, entre os talões palmar/plantar ou dorsal. $\mathrm{O}$ seu aspecto pode variar e sua fase de cura é caracterizada por uma crosta seca, indolor e firmemente aderida à pele saudável subjacente (Refaai et al, 2013; Palmer e O'Connell, 2015). O local de predileção da DD ocorre, provavelmente, devido à conformação anatômica, a qual possibilita o acúmulo de sujidade, gerando um ambiente com menor tensão de oxigênio e, consequentemente, favorecendo o desenvolvimento dos microrganismos envolvidos na etiopatogenia da DD (Greenough, 1997).

A lesão pode ser extremamente dolorosa e, dependendo da severidade das lesões, o animal pode apresentar claudicação severa e pisar nas pinças dos cascos (Fajt e Apley, 2001; Refaai et al, 2013; Palmer e O'Connell, 2015).

Döpfer et al. (1997) classificam a DD de M1 a M4.1, sendo M1 uma lesão ulcerativa em estágio inicial (0-2 $\mathrm{cm}$ de diâmetro), que não é dolorosa à palpação; M2 é a fase ulcerativa clássica, com um diâmetro maior que $2 \mathrm{~cm}$ e muitas vezes dolorosa à palpação; M3 é a fase de cura, com uma lesão coberta por uma crosta; M4 é a fase crônica, caracterizada por hiperqueratose ou proliferação de superfície e geralmente não dolorosa; M4.1 descreve uma lesão crônica, com uma pequena área de ulceração. Refaai et al. (2013) encontraram aumentos significativos da espessura da epiderme nas fases M2, M3 e M4, sendo que M3 e M4 também foram caracterizadas porum grande aumento de queratina. Segundo Souza (2005), as lesões provocadas pela DD podem ser classificadas macroscopicamente em três formas: hiperplásica (grau 1), ulcerativa e proliferativa (grau 2) ou papilomatosa (grau 3). Outras formas de classificação também são descritas na literatura.

Quanto ao curso e duração da doença, Rebhun et al. (1980) observaram um curso médio de 14 a 21 dias entre as mudanças de fase. Krull et al. (2014) encontraram uma média de 135 dias para a DD mudar de fase, com lesões permanecendo no mesmo estágio por até dois anos ou mais. Somers et al. (2005) mostraram que as lesões ulcerativas (fase M2) podem persistir por longos períodos, podendo chegar até meses em animais que não foram submetidos ao tratamento. Souza (2005) observou que lesões de grau 1 demoraram em média 28 dias até assumirem a forma 2 , que por sua vez demandou em média 45 dias para atingir o grau 3. Essas lesões em diferentes estágios clínicos podem coexistir em um mesmo animal (Nascimento et al, 2015). Losinger (2006) demonstrou que algumas espécies de Treponema podem causar imunossupressão de macrófagos e prejudicar não só a resposta imune inata, mas também a reparação da lesão, explicando em parte a progressão e persistência da doença.

\section{Etiologia da dermatite digital}

A etiologia da DD ainda não está totalmente esclarecida, mas é consenso que se trata de uma doença bacteriana, uma vez que as lesões regridem após tratamento antibiótico e que a participação de vírus e fungos foi descartada por vários estudos (Brandt et al., 2011; Berry et al., 2012). A DD é uma doença polimicrobiana pela ampla variedade de bactérias que foram isoladas, no entanto, o papel de diferentes espécies não é bem conhecido. As bactérias isoladas e identificadas variam de Fusobacterium necrophorus, Guggenheimella, Prevotella, Camplyobacter, Clostridium, Mycoplasma e Dichelobacter nodosus a várias espiroquetas (Klitgaard et al., 2008, 2013).

Diversos relatos demonstram um predomínio de bactérias do gênero Treponema e que estas são o grupo de bactérias mais abundante na lesão, principalmente nas partes mais profundas, sugerindo que são patógenos invasivos e que não simplesmente colonizam o tecido infectado 
(Klitgaard et al, 2013; Nielsen et al, 2016; Moreira et al., 2018). Até hoje, mais de 20 filotipos diferentes de Treponema foram identificados em biópsias de DD (Wilson-Welder et al., 2015a).

Os filotipos mais comuns foram T. vincentii/T. medium, T. phagedenis, T. denticola/T. putidumlike, T. refringens/T. tipo calligyrum, T. pedis-like e T. denticola/T. putidum-like, mas outras pesquisas expandiram essa lista, incluindo T. brennaborense, $T$. maltophilum-like e T. zuelzerae (Evans et al., 2008; Yano et al., 2010; Klitgaard et al., 2013). Outros filotipos ainda não cultivados foram identificados pelo prefixo PT, através de técnicas moleculares utilizando o $16 \mathrm{~S}$ rDNA, e definidos como aglomerados de treponemas, em que a sequência 16S rDNA difere em $\sim 2 \%$ de espécies conhecidas e que são $\geq 99 \%$ semelhantes a outros membros do cluster (Klitgaard et al., 2013). Estes estudos foram realizados em diferentes países da Europa, nos EUA e no Japão, e apresentam uma variação dos treponemas identificados pelo $16 \mathrm{~S}$ rDNA, o que pode indicar uma variação regional/geográfica nos treponemas associados a DD.

Os primeirosestudosquebuscaram compreender a etiologia da DD demonstravam a presença maciça de espiroquetas do gênero Treponema, além de grande quantidade de Campylobacter faecalis, utilizando as técnicas de imunofluorescência e coloração pela prata (Döpfer et al., 1997).

O primeiro estudo no Brasil encontrou $T$. phagedenis, T. medium e T. vicentii juntos em 95,45\% das lesões, e todos os grupos de Treponema, incluindo T. denticola e T. putidum, foram achados juntos em 81,82\% das biópsias de DD (Nascimento et al. ,2015). Ainda no Brasil, Moreira et al. (2018) demonstraram que a microbiota dominante das lesões de DD de bovinos que estão a pasto durante todo o ano também possui os Treponemas como a principal bactéria. Foram identificados os filotipos T. pedis, T. refringens, T. denticula, T. phagedenis, T.medium, T. porcinum e T. zuelzerae na lesão de animais provenientes de cinco fazendas distintas no interior de Minas Gerais.

Em um dos poucos estudos nos quais foi realizado o isolamento de Treponemas em lesões de DD, Lima (2008) conseguiu cultivar e identificar a espécie $T$. pedis através da análise de sequências de genes $16 \mathrm{~S}$ RNAr. Além desta, as bactérias Leptospira broomi,
L. fainei, L. licerasiae, L. wolffii, Corynebacterium appendicis, Cupriavidus gilardii, Enterococcus casseliflavus e E. gallinarum também foram isoladas.

Estudos mais novos, utilizando técnicas de diagnóstico molecular, comprovam o papel dos Treponemas na etiologia da DD. Evans et al. (2008) aplicaram o método de PCR para fragmentos do gene 16s rRNA e imunohistoquímica. Os filotipos T. medium/T. vincentii, T. phagedenis e T. putidum/T. denticola foram encontrados em 96,1\%, 98\% e $76,5 \%$ das lesões, respectivamente, com os três filotipos aparecendo juntos em 74,5\% das lesões. Verificou-se a presença de Treponemas na pele saudável dos animais, porém estes não eram os mesmos filotipos encontrados nas áreas de lesão.

Klitgaard et al. (2013), utilizando sequenciamento de nova geração e análise de FISH, realizaram biópsias de animais com DD provenientes de dez rebanhos localizados em regiões diferentes da Espanha, totalizando 36 biópsias. Macroscopicamente, mais de $60 \%$ das lesões apresentavam-se na fase ulcerativa (M2) e o restante estava em diferentes fases da lesão. Foram detectados nesse estudo T. phagedenis, T. medium, T. vicentii, T. denticola, T. pedis, T. maltophilum, T. refringens, e também foram encontrados 15 diferentes filotipos de Treponema que não haviam sido previamente identificados. Em média, nas 36 amostras de DD foram encontrados oito filotipos de Treponema por lesão.

Os cinco Treponemas mais prevalentes encontrados no estudo de Klitgaard et al. (2013) foram T. denticola (45\% das amostras), T. pedis (45\% das amostras), T. phagedenis (20\% das amostras), $T$. medium (18\% das amostras) e T. refringens (17\% das amostras). Nas partes mais profundas e no meio das lesões, a presença de outras bactérias que não pertenciam ao gênero Treponema foi insignificante. Apesar de também serem citados como envolvidos na lesão, outros agentes como $D$. nodosus e $F$. necrophorum não foram identificados no estudo (Knappe-Poindecker et al., 2014).

Rasmussen et al. (2012) realizaram 90 biópsias de lesões de DD e 24 biópsias da pele saudável de animais provenientes de um rebanho leiteiro da Noruega e de seis rebanhos leiteiros da Dinamarca. Todas as lesões apresentaram, em média, sete filotipos de Treponema e em seis delas foram 
encontrados mais de 12 filotipos. D. nodosus esteve presente em $51 \%$ das lesões e foi encontrado também em três amostras de pele aparentemente saudáveis. Em outras duas amostras de pele saudável, verificou-se a presença de Treponemas associados ao $D$. nodosus.

Nielsen et al. (2016) avaliaram 27 animais com DD e 10 animais sem a presença da lesão, onde se observou clara distinção entre a microbiota do tecido saudável e o tecido afetado por DD. As bactérias dos gêneros Treponema, Mycoplasma, Fusobacterium e Porphyromonas eram as que melhor explicavam a diferença encontrada entre o microbioma das biópsias de lesão e biópsias de animais sadios. Este gêneros eram mais abundantes nas biopsias de lesão. Os filos mais prevalentes encontrados na pele saudável foram Firmicutes, Actinobacteria, Proteobacteria e Bacteroidetes. Em nível de famílias, Moraxellaceae, Corynebacteriaceae, Lachnospiraceae e Ruminococcaceae foram as mais abundantes em amostras do controle. Análises de FISH indicaram que espécies pertencentes ao gênero Treponema foram as bactérias dominantes na parte profunda da lesão, constituindo aproximadamente $90 \%$ da microbiota infectante. Foram encontrados 15 filotipos diferentes, sendo T. phagedenis e T. refringens os mais abundantes. F necrophorum e $P$. levii foram principalmente observados nas partes superficiais da epiderme. D. nodosus, outra bactéria também suspeita de estar envolvida no desenvolvimento de DD (Rasmussen et al, 2012), foi identificado por análises de FISH em 12 das amostras, apesar de ausente ou abaixo do limite de detecção na sequência de dados.

Os diversos trabalhos mostram a DD como uma doença "multitreponemal", porém não está esclarecido se os Treponemas sozinhos são capazes de causar a lesão ou se existe uma relação simbiótica com outros agentes. Dentre as diferentes bactérias que foram encontradas nas lesões de DD, nenhuma foi identificada de forma consistente nos diversos trabalhos; por isso, não é possível determinar seu real papel na lesão de DD e a importância de qualquer uma delas no desenvolvimento da lesão (Rasmussen et al., 2012; Santos et al., 2012; Moreira et al., 2018).

Entre as outras bactérias presentes nas lesões, D. nodosus parece desempenhar, possivelmente com a Treponema, um papel importante no desenvolvimento e na expansão da lesão, (Rasmussen et al., 2012; Moreira et al., 2018). D. nodosus e $F$. necrophorum são reconhecidos mundialmente como os agentes causadores da podridão dos cascos em ovinos e caprinos (Moore et al., 2005). D. nodosus produz proteases extracelulares que podem causar danos ao tecido e facilitar a penetração e colonização de bactérias do gênero Treponema. Dessa forma, esses dois agentes podem agir sinergicamente, principalmente na fase inicial da doença (WilsonWelder et al., 2015b). Knappe-Poindecker et al. (2014) avaliaram 14 rebanhos leiteiros na Noruega e encontraram $D$. nodosus como a bactéria mais prevalente nas lesões de dermatite interdigital e erosão de talão. Sullivan et al. (2015) encontraram $D$. nodosus e F. necrophorum respectivamente em $71 \%$ e $44 \%$ das lesões de DD avaliadas e em mais de $20 \%$ das amostras de tecidos de pés saudáveis. Capion et al. (2008) realizaram 132 biópsias de DD e, utilizando a técnica de FISH, também encontraram em $29 \%$ das lesões a presença de $D$. nodosus.

A maioria dos trabalhos não obteve sucesso em demonstrar diferenças na população bacteriana em lesões com classificações diferentes segundo o que foi proposto por Döpfer et al. (1997). Uma exceção é o trabalho de Zinicola et al. (2015a), no qual foi coletado um total de 140 amostras feitas a partir de 89 vacas leiteiras, em três propriedades rurais diferentes. A classificação de pontuação das lesões de DD foi adaptada do método descrito por Döpfer et al. (1997). Foram coletadas amostras da lesão em diferentes formas e amostras de pele saudável. Verificou-se aumento das bactérias do gênero Treponema, como T. denticola, T. maltophilum, T. medium, T. paraluiscuniculi, T. phagedenis e T. putidum, em lesões DD ativas quando comparadas com a pele saudável e com lesões de DD inativas. As lesões de DD inativas, além de apresentarem uma menor proporção de Treponemas, exibiram um aumento marcante das bactérias Porphyromonas sp., Alkaliphilus crotonatoxidans, Sedimentibacter hydroxybenzoicus e Filifactor villosus quando comparadas às lesões de DD ativas. Os microbiomas da pele saudável foram diversos, mas dominados por bactérias pertencentes ao filo Firmicutes e Actinobacteria. A bactéria Candidatus Aemobophilus asiaticus foi encontrada em grande proporção em todas as fases de DD. 
Outro trabalho que encontrou diferença na população microbiana localizada em lesões com graus diferentes foi o de Krull et al. (2014). Este trabalho é composto por um estudo longitudinal de três anos, onde os autores coletaram 48 biópsias de DD a partir de 26 animais em lactação. No início do estudo, a prevalência de DD no rebanho foi estimada em $50 \%$. Não foi utilizada nenhuma medida curativa ou preventiva para controlar DD nas vacas, o que permitiu a observação do desenvolvimento da lesão na ausência de intervenção. Os autores desenvolveram um sistema independente de classificação da DD, onde o estágio zero representa a pele bovina normal e os estágios A1/A2 e B1/ B2 representaram variações morfológicas de desenvolvimento das lesões de DD, sendo os estágios três e quatro as formas clínicas da doença responsáveis pela claudicação, e as lesões que receberam tratamento são apresentadas como estágio cinco.

Neste mesmo estudo (Krull et al., 2014), foram encontradas na pele saudável as famílias Staphylococcacea, Streptococcaceae, Bacteroidaceae, Corynebacteriaceae e Porphyromonadaceae, as quais foram gradativamente substituídas por outras à medida que a lesão progrediu. As espiroquetas do gênero Treponema foram predominantes nos estágios três e quatro da lesão, correspondendo a $94,3 \%$ das bactérias encontradas, principalmente $T$. denticola, T. phagedenis, T. pedis, T. medium e T. PT8. A família Mycoplasmataceae também foi encontrada em grande quantidade nas fases três e quatro da DD. Nas fases A1/A2 e B1/B2 foram encontrados Treponemas, mas em menor proporção do que nas fases ulcerativas da doença. No estágio 5 (lesões que foram submetidas ao tratamento) ocorreu um rápido declínio da população de Treponemas, e a microbiota da lesão foi semelhante a que foi encontrada na pele íntegra.

Em outro estudo, 16 amostras de biópsias de oito vacas leiteiras foram avaliadas e os filos Firmicutes, Actinobacteria e Chordata foram encontrados em grande proporção na pele saudável. As Spirochetas e Bacteroidetes foram altamente prevalentes em amostras de DD ativa e inativa, respectivamente. Os filotipos mais abundantes de Treponemas encontrados foram: T. phagedenis, T. denticola, $T$. vincentii e T. pallidum (Zinicola et al., 2015b).
A indução experimental da DD é fundamental para ajudar a esclarecer sua etiologia, porém as tentativas de induzir a doença através da inoculação de culturas puras das diferentes bactérias encontradas na DD foram largamente malsucedidas (Wilson-Welder et al., 2015b). Gomez et al. (2012) e Krull et al. (2016), no entanto, reproduziram com sucesso a doença por diferentes métodos. Após diversos testes, a metodologia mais sucedida (95\% de sucesso) foi inocular em pele saudável um macerado de lesão de DD ativa, enfaixar para produzir um ambiente anaeróbico e manter o local umedecido. Após um período de 12 a 25 dias nestas condições, os autores conseguiram induzir lesões de DD e detectaram a presença de Treponema (Krull et al., 2016).

O trabalho de Krull et al. (2016) também auxilia a esclarecer se seria necessária a presença de alguma lesão prévia no epitélio para a ocorrência da DD. A possibilidade de induzir a doença experimentalmente, sem a necessidade de lesionar a pele anteriormente, pode ser um indicativo de que apenas manter o ambiente úmido seja suficiente para causar uma alteração na pele suficiente para que os Treponemas possam penetrar. Entretanto, alguns autores afirmam o contrário, sustentando que os Treponemas não seriam capazes de penetrar em pele íntegra e que lesões prévias, sejam de origem física ou química, seriam necessárias (Wilson-Welder et al, 2015a). Este ponto ainda é pouco elucidado e mais pesquisas são necessárias.

Fazendo um paralelo com doença periodontal em humanos, na qual os Treponemas também possuem papel fundamental, Lux et al. (2001) mostraram que a capacidade de penetrar nos tecidos é um importante fator de virulência de espiroquetas patogênicas e que sua motilidade permite que elas invadam o tecido e migrem para locais favoráveis à sua proliferação. Embora seja evidente que Treponemas patogênicos migrem para o interior dos tecidos, é ainda pouco esclarecido se esses movimentos são aleatórios ou dirigidos por um sistema de quimiotaxia. Além disso, vários trabalhos já mostraram que bactérias do gênero Treponema podem causar algum grau de depressão das respostas imunológicas, prejudicando não só a resposta imune inata, mas também a reparação tecidual (Losinger et al., 2006). Se todos esses 
fatores de virulência encontrados nos Treponemas causadores da doença periodontal em seres humanos estiverem presentes naqueles que causam a DD, é possível que este agente possa colonizar sozinho e lesar o tecido sadio através da produção de enzimas proteolíticas e colagenolíticas, formando, assim, a lesão de DD.

Os estudos, entretanto, apontam para uma outra direção, pois as tentativas de induzir a doença com culturas puras de Treponema foram inconsistentes e produziram lesões pequenas e sem a gravidade demonstrada pela doença. Neste sentido, uma hipótese é que o $D$. nodosus aja produzindo proteases extracelulares que podem causar danos ao tecido, facilitando a penetração e colonização de bactérias do gênero Treponema. Dessa forma, esses dois agentes podem agir sinergicamente, principalmente na fase inicial da doença (WilsonWelder et al., 2015a).

\section{Entendimento atual sobre a transmissão, reservatórios e rotas de transmissão}

A transmissão entre animais dentro da mesma fazenda é ainda pouco elucidada, apesar de a DD ser reconhecidamente uma doença infecciosa. Diferentes estudos tentaram identificar bactérias relacionadas à DD nas fezes, reto, rúmen e no ambiente de animais com a presença da lesão e obtiveram resultados divergentes (Wilson-Welder et al., 2015b).

Vários Treponemas têm sido relatados por serem da microbiota comensal dos bovinos, vivendo em simbiose no trato gastrointestinal, como T. bryantii e T. saccharophilum, que foram isolados a partir do rúmen de vacas leiteiras (Paster e Canale-Parola, 1982). Shibahara et al. (2002) encontraram a presença de T. pallidum no cólon de bovinos abatidos no Japão. Vários autores consideram a hipótese de que o líquido ruminal, as fezes e a cavidade oral funcionem como reservatório para DD dentro da propriedade e que bactérias presentes nesses locais possam contaminar o ambiente, sendo este um real veículo de transmissão da doença (Evans et al., 2012; Nascimento et al., 2015; Zinicola et al., 2015a).

Apesar de ambientes úmidos e com grande quantidade de matéria orgânica poderem aumentar a incidência e disseminação da DD, poucos trabalhos conseguiram isolar Treponema de amostras ambientais (Klitgaard etal.,2014).Comoa microbiota da pele íntegra dos pés dos bovinos é bem diferente da encontrada nas lesões de DD, permanece incerto se os tecidos saudáveis dos pés são o reservatório de infecção primária ou se existem outras fontes de contaminação (Evans et al., 2008).

Nascimento et al. (2015) coletaram fluido ruminal de 15 vacas leiteiras portadoras de DD em sete diferentes propriedades, e utilizando a técnica de PCR, encontraram pelo menos um dos filotipos patogênicos para DD em $60 \%$ das amostras. 0 T. phagedenis foi o mais prevalente (40\%), seguido por T. medium/T. vincentii $(33,33$ $\%$ e e $T$. denticola/T. putidum (26,67\%). Em duas vacas foram identificados todos esses Treponemas no fluido de rúmen, porém nem todas as espécies presentes nas lesões foram identificadas no fluido ruminal. Zinicola et al. (2015a), ao coletarem oito amostras de fluido ruminal e 14 amostras fecais de vacas leiteiras em propriedades com a presença da DD, encontraram as mesmas espécies de Treponema (T. denticola, T. maltophilum, T. medium, T. putidum, T. phagedenis e T. paraluiscuniculi) que estavam presentes nas lesões de DD em amostras de fezes e de rúmen dos animais.

Klitgaard et al. (2014) realizaram biópsias de lesões de DD e coletaram amostras de fezes e de ambiente de seis rebanhos com alta prevalência da doença e de um rebanho livre. No rebanho livre não foi encontrado nenhum Treponema relacionado à DD nas amostras de fezes e de ambiente. Nas seis propriedades com a presença da lesão foram encontrados Treponemas relacionados à DD nas amostras ambientais e fecais, porém a prevalência destes foi extremamente baixa, sendo inferior a 0,5\%. Em um estudo na Inglaterra, Evans et al. (2011) encontraram sete espécies de Treponemas em amostras de diferentes locais do trato gastrointes-tinal (rúmen, omaso, intestino grosso e fezes) após o abate dos animais, porém nenhuma delas havia sido relacionada às espécies encontradas na DD bovina.

Evans et al. (2011) analisaram 368 amostras, entre material colhido do ambiente e conteúdo do trato gastrointestinal bovino, utilizando ensaios de PCR para os três filotipos de Treponema mais 
encontrados nas lesões (T. medium, T. phagedenis e T. pedis). Todas as amostras ambientais e amostras de conteúdo do trato gastrointestinal foram negativas. No entanto, identificou-se Treponemas relacionados à DD em duas regiões específicas dos animais, o tecido da cavidade oral $(14,3 \%$ das amostras testadas) e o tecido retal $(14,8 \%$ das amostras testadas). Apesar de positivas, estas amostras possuíam proporções relativamente baixas destas bactérias e não havia nenhuma lesão macroscópica nesses locais durante a coleta.

Sullivan et al. (2015) pesquisaram a presença de Treponemas na cavidade oral, tecidos retais e fezes de bovinos e ovinos. Entre os 40 ovinos avaliados, um apresentou Treponemas associados à DD na cavidade oral, três apresentaram no tecido retal e 22 diferentes filotipos de Treponemas foram isolados a partir das fezes dos 40 ovinos avaliados, no entanto, nenhum desses Treponemas encontrados foi considerado patogênico. Os filotipos encontrados nos tecidos orais e retais dos ovinos foram T. pedis e T. phagedenis. Não foi encontrado Treponema na mucosa retal e nas fezes dos 40 bovinos avaliados. Verificou-se, entretanto, a presença de Treponemas na cavidade oral de quatro animais. 0 filotipo associado a DD presente na cavidade oral de bovinos foi T. phagedenis.

Clegg et al. (2015) relataram um aumento nos casos de claudicação em alces selvagens na América do Norte e realizaram sete biópsias de pele nesses animais, sendo quatro de alces clinicamente sadios (grupo controle) e três de alces com uma lesão semelhante à DD. Utilizando a técnica de PCR, verificaram a presença de Treponemas nas lesões, sendo T. vincentii, T. phagedenis e T. pedis encontrados nas três biópsias de lesão; não foram encontrados Treponemas na pele íntegra. Como este foi o primeiro relato de DD associado à Treponema em animais selvagens, uma das hipóteses levantadas pelos autores foi de as pastagens utilizadas pelos alces terem sido anteriormente usadas por bovinos e ovinos, sugerindo que o ambiente pode atuar como potencial reservatório para essas bactérias.

Embora tenha havido evidências do envolvimento do trato gastrointestinal, são necessários mais trabalhos para esclarecer as vias de transmissão definitivas e o seu real papel como reservatório dos
Treponemas causadores da DD. A questão de como essas bactérias encontradas com uma prevalência tão baixa no ambiente podem ser tão bem-sucedidas em infectar um rebanho ainda precisa ser melhor elucidada (Evans et al., 2012; Klitgaard et al., 2014).

\section{Conclusão}

Conclui-se que a etiologia da DD é "polimicrobiana e multitreponemal". Existem vários filotipos de Treponema envolvidos na etiologia da DD, porém entre os conhecidos, o T. phagedenis e o T. pedis merecem destaque pela sua frequência e densidade. Existe um grande número de filotipos de Treponema spp. circulando no ambiente e presentes nas lesões de DD e no trato gastrointestinal dos bovinos, sugerindo que a microbiota do trato gastrointestinal e o ambiente da fazenda podem atuar como reservatórios de bactérias envolvidas na patogênese da DD.

\section{Referências}

Berry SL, Read DH, Famula TR, Mongini A, Döpfer D. Longterm observations on the dynamics of bovine digital dermatitis lesions on a California dairy after topical treatment with lincomycin $\mathrm{HCl}$. Vet J. 2012;193(3): 654-8.

Blowey RW, Sharp MW. Digital dermatitis in dairy cattle. Vet Rec. 1988;122(21):505-8.

Borges JRJ, Pitombo CA, Santiago SS, Ribeiro PN, Ronconi MA. Incidência de afecções podais em bovinos leiteiros submetidos a diferentes sistemas de manejo. Arq Esc Med Vet. 1992;15:34-42.

Brandt S, Apprich V, Hackl V, Tober R, Danzer M, Kainzbauer $C$, et al. Prevalence of bovine papillomavirus and Treponema DNA in bovine digital dermatitis lesions. Vet Microbiol. 2011;148(2-4):161-7.

Capion N, Thamsborg SM, Enevoldsen C. Prevalence of foot lesions in Danish Holstein cows. Vet Rec. 2008;163(3):80-5. 
Cheli RE, Mortellaro CM. Digital dermatitis in cattle. 8th International Meeting on Diseases of Cattle; 9-13 set 1974; Milão, Itália. Piacentina: Gallarati; 1975. p. 208-13.

Clegg SR, Mansfield KG, Newbrook K, Sullivan LE, Blowey RW, Carter SD, et al. Isolation of digital dermatitis Treponemes from hoof lesions in Wild North American Elk (Cervus elaphus) in Washington State, USA. J Clin Microbiol. 2015;53(1):88-94.

Döpfer D, Koopmans A, Meijer FA, Szakáll I, Schukken YH, Klee W, et al. Histological and bacteriological evaluation of digital dermatitis in cattle, with special reference to Spirochaetes and Campylobacter faecalis. Vet Rec. 1997;140(24):620-3.

Evans NJ, Brown JM, Demirkan I, Murray RD, Vink WD, Blowey RW, et al. Three unique groups of Spirochaetes isolated from digital dermatitis lesions in UK cattle. Vet Microbiol. 2008;130(1-2):141-50.

Evans NJ, Brown JM, Murray RD, Getty B, Birtles RJ, Hart $\mathrm{CA}$, et al. Characterization of novel bovine gastrointestinal tract Treponema isolates and comparison with bovine digital dermatitis Treponemes. Appl Environ Microbiol. 2011;77(1):138-47.

Evans NJ, Timofte D, Isherwood DR, Brown JM, Williams JM, Sherlock K, et al. Host and environmental reservoirs of infection for bovine digital dermatitis Treponemes. Vet Microbiol. 2012;156(1-2):102-9.

Fajt VR, Apley MD. Antimicrobial issues in bovine lameness. Vet Clin North Am Food Anim Pract. 2001;17(1):159-73.

Gomez A, Cook NB, Bernardoni ND, Rieman J, Dusick AF, Hartshorn $\mathrm{R}$, et al. An experimental infection model to induce digital dermatitis infection in cattle. J Dairy Sci. 2012;95(4):1821-30.

Greenough PR, Weaver AD. Lameness in cattle. 3 ed. Philadelphia: Saunders; 1997. 336 p.

Klitgaard K, Boye M, Capion N, Jensen TK. Evidence of multiple Treponema phylotypes involved in bovine digital dermatitis as shown by $16 \mathrm{~S}$ rRNA gene analysis and fluorescence in situ hybridization. J Clin Microbiol. 2008;46(9):3012-20.
Klitgaard K, Bretó AF, Boye M, Jensen TK. Targeting the Treponemal microbiome of digital dermatitis infections by high-resolution phylogenetic analyses and comparison with fluorescent in situ hybridization. J Clin Microbiol. 2013;51(7):2212-9.

Klitgaard K, Nielsen MW, Ingerslev HC, Boye M, Jensen TK. Discovery of bovine digital dermatitis-associated Treponema spp. in the dairy herd environment by a targeted deep-sequencing approach. Appl Environ Microbiol. 2014;80(14):4427-32.

Knappe-Poindecker M, Gilhuus M, Jensen TK, Vatn S, Jørgensen HJ, Fjeldaas T. Cross-infection of virulent Dichelobacter nodosus between sheep and co-grazing cattle. Vet Microbiol. 2014;170(3-4):375-82.

Krull AC, Cooper VL, Coatney JW, Shearer JK, Gorden PJ, Plummer PJ. A highly effective protocol for the rapid and consistent induction of digital dermatitis in holstein calves. PLoS One. 2016;11(4):e0154481.

Krull AC, Shearer JK, Gorden PJ, Cooper VL, Phillips GJ, Plummer PJ. Deep sequencing analysis reveals the temporal microbiota changes associated with the development of bovine digital dermatitis. Infect Immun. 2014;82(8):3359-73.

Lima SD. Microbiota presente em abscesso de sola e dermatite digital em bovinos leiteiros de Minas Gerais [tese]. Belo Horizonte: Universidade Federal de Minas Gerais; 2008.

Losinger WC. Economic impacts of reduced milk production associated with papillomatous digital dermatitis in dairy cows in the USA. J Dairy Res. 2006;73(2):244-56.

Lux R, Miller JN, Park NH, Shi W. Motility and chemotaxis in tissue penetration of oral epithelial cell layers by Treponema denticola. Infect Immun. 2001;69(10):6276-83.

Moore LJ, Woodward MJ, Grogono-Thomas R. The occurrence of Treponemes in contagious ovine digital dermatitis and the characterisation of associated Dichelobacter nodosus. Vet Microbiol. 2005;111(3-4):199-209. 
Moreira TF, Facury Filho EJ, Carvalho AU, Strube ML, Nielsen MW, Klitgaard K, et al. Pathology and bacteria related to digital dermatitis in dairy cattle in all year round grazing system in Brazil. PLoS One. 2018;13(3): e0193870.

Nascimento LV, Mauerwerk MT, Santos CL, Barros Filho IR, Birgel Jr EH, Sotomaior CS, et al. Treponemes detected in digital dermatitis lesions in Brazilian dairy cattle and possible host reservoirs of infection. J Clin Microbiol. 2015;53(6):1935-7.

Nielsen MW, Strube ML, Isbrand A, Al-Medrasi WDHM, Boye M, Jensen TK, et al. Potential bacterial core species associated with digital dermatitis in cattle herds identified by molecular profiling of interdigital skin samples. Vet Microbiol. 2016;186:139-49.

Palmer MA, O'connell NE. Digital Dermatitis in Dairy Cows: A Review of Risk Factors and Potential Sources of Between-Animal Variation in Susceptibility. Animals (Basel). 2015;5(3):512-35.

Paster BJ, Canale-Parola E. Physiological diversity of rumen spirochetes. Appl Environ Microbiol. 1982;43(3): 686-93.

Rasmussen M, Capion N, Klitgaard K, Rogdo T, Fjeldaas $\mathrm{T}$, Boye $\mathrm{M}$, et al. Bovine digital dermatitis: Possible pathogenic consortium consisting of Dichelobacter nodosus and multiple Treponema species. Vet Microbiol. 2012;160(1-2):151-61.

Rebhun WC, Payne RM, King JM, Wolf M, Begg SN. Interdigital papilomatosis in dairy cattle. J Am Vet Med Assoc. 1980;177(5):437-40.

Refaai W, Ducatelle R, Geldhof P, Mihi B, El-shair M, Opsomer G. Digital dermatitis in cattle is associated with an excessive innate immune response triggered by the keratinocytes. BMC Vet Res. 2013;9:193.

Rodriguez-Lainz A, Melendez-Retamal P, Hird DW, Read DH, Walker RL. Farm- and host-level risk factors for papillomatous digital dermatitis in Chilean dairy cattle. Prev Vet Med. 1999;42(2):87-97.
Santos TM, Pereira RV, Caixeta LS, Guard CL, Bicalho RC. Microbial diversity in bovine papillomatous digital dermatitis in holstein dairy cows from upstate New York. FEMS Microbiol Ecol. 2012;79(2):518-29.

Shibahara T, Ohya T, Ishii R, Ogihara Y, Maeda T, Ishikawa $Y$, et al. Concurrent spirochaetal infections of the feet and colon of cattle in Japan. Aust Vet J. 2002;80(8):497-502.

Somers JGCJ, Frankena K, Noordhuizen-Stassen EN, Metz JHM. Risk factors for digital dermatitis in dairy cows kept in cubicle houses in The Netherlands. Prev Vet Med. 2005;71(1-2):11-21.

Souza RC. Enfermidades podais em Vacas Leiteiras: Eficiência e Custos de Tratamentos, Efeitos na Produção e Reprodução, Histopatologia e Aspectos Econômicos [tese]. Belo Horizonte: Universidade Federal de Minas Gerais; 2005. 92 p.

Sullivan LE, Blowey RW, Carter SD, Duncan JS, GroveWhite DH, Page P, et al. Presence of digital dermatitis Treponemes on cattle and sheep hoof trimming equipment. Vet Rec. 2014;175(8):201.

Sullivan LE, Evans NJ, Blowey RW, Grove-White DH, Clegg SR, Duncan JS, et al. A molecular epidemiology of treponemes in beef cattle digital dermatitis lesions and comparative analyses with sheep contagious ovine digital dermatitis and dairy cattle digital dermatitis lesions. Vet Microbiol. 2015;178(1-2):77-87.

USDA. Dairy 2007. Part IV: Reference of dairy cattle health and management practices in the United States. Fort Collins: USDA APHIS; 2009. 178 p.

Wilson-Welder JH, Alt DP, Nally JE. The etiology of digital dermatitis in ruminants: recent perspectives. Vet Med (Auckl). 2015a;6:155-64.

Wilson-Welder JH, Alt DP, Nally JE. Digital Dermatitis in cattle: current bacterial and immunological findings. Animals (Basel). 2015b;5(4):1114-35. 
Yano T, Moe KK, Yamazaki K, Ooka T, Hayashi T, Misawa $\mathrm{N}$. Identification of candidate pathogens of papillomatous digital dermatitis in dairy cattle from quantitative $16 \mathrm{~S} \mathrm{r}$ RNA clonal analysis. Vet Microbiol. 2010;143(2-4):352-62.

Zinicola M, Higgins H, Lima S, Machado V, Guard C, Bicalho R. Shotgun Metagenomic Sequencing reveals functional genes and microbiome associated with bovine digital dermatitis. PLoS One. 2015b;10(7):e0133674.

Zinicola M, Lima F, Lima S, Machado V, Gomez M, Döpfer $D$, et al. Altered microbiomes in bovine digital dermatitis lesions, and the gut as a pathogen reservoir. J PLoS One. 2015a;10(3):e0120504. 